Márcia Cristina Maciel de Aguiar Ohttps://orid. org/0000-0001-7797-4530

Milena Pereira Pondé

Ohtps://orid.org/0000-0002-1292-5487

\section{Autism: impact of the diagnosis in the parents}

\author{
Autismo: impacto do diagnóstico nos pais
}

DOI: $10.1590 / 0047-2085000000276$

\section{ABSTRACT}

Objective: To understand how parents react to the diagnosis of autism in their child, and the manner in which the diagnosis was revealed, as well as the method through which the researcher perceived this communication. Methods: A qualitative, narrative approach was used. Semi-structured interviews were held with 21 mothers and 9 fathers of children with autism spectrum disorder (ASD) enrolled in a special needs school in Salvador, Bahia, Brazil. In another setting, a specialist university service for the diagnosis of autism located in the same city, data were collected from 11 mothers and 5 fathers receiving diagnosis using ethnographic participant observation. Analysis categories were established, and the data interpreted. Results: The categories selected were: "in search of a diagnosis", "impact of receiving the diagnosis", "patterns of diagnosis communication", and "coping strategies". Conclusion: The diagnosis of autism is often delayed due to doctors' unpreparedness. Awareness of their child's diagnosis exerts a negative emotional impact on parents, which can be softened using coping strategies and diagnosis communication that offers technical information, offers emotional support and provides hope regarding the child's development. Parents need to be cared for in order to provide for the needs of their children at the moment of diagnosis and throughout the entire process of caring for individuals with ASD.

\section{KEYWORDS}

Autism spectrum disorder, family, coping.

\section{RESUMO}

Objetivo: Conhecer como os pais reagem ao diagnóstico de autismo em seu filho e ao modo em como esse foi revelado, bem como a forma que o pesquisador percebeu essa comunicação. Métodos: Qualitativo, abordagem narrativa. Foram feitas entrevistas semiestruturadas com 21 mães e 9 pais com filhos com transtorno do espectro autista (TEA) de uma escola especial em Salvador, Bahia, Brasil, e utilizada técnica etnográfica de observação participante em um serviço universitário especializado em diagnóstico de autismo, na mesma cidade, com 11 mães e 5 pais. As categorias de análise foram elaboradas e os dados, interpretados. Resultados: Foram selecionadas as categorias "em busca do diagnóstico", "impacto na recepção do diagnóstico", "padrões da comunicação diagnóstica" e "estratégias de enfrentamento". Conclusão: $O$ diagnóstico de autismo é tardio devido ao pouco conhecimento e/ou habilidade dos profissionais médicos. Saber do diagnóstico dos filhos produz impacto emocional negativo nos pais, o que pode ser amenizado com estratégias de enfrentamento e comunicação diagnóstica que passe informações técnicas, ofereça suporte emocional, além de esperança quanto ao desenvolvimento do filho. Os pais precisam ser cuidados, para cuidarem dos filhos, no momento do diagnóstico e em todo o percurso de assistência às pessoas com TEA.

PALAVRAS-CHAVE

Transtorno do espectro autista, família, enfrentamento. 


\section{INTRODUCTION}

Autism spectrum disorder (ASD) is a neurodevelopmental disorder characterized by impaired social interaction, impaired verbal and non-verbal communication skills, stereotypical behaviors and restricted interests. Symptoms vary, ranging from mild impairment to being completely unable to interact or communicate'. In the majority of cases, the parents are the first to notice their child's developmental difficulties ${ }^{2,3}$, which are generally related to deficits in socialization skills, inflexibility and/or behavioral issues ${ }^{2}$ and delayed verbal language ${ }^{4}$, with the absence or delayed speech being the main symptom leading parents to seek professional help $p^{5}$.

Reaching a diagnosis of autism is not a simple process, since, in addition to the wide diversity of its manifestations and the severity of its symptoms, there are also comorbidities ${ }^{6-9}$. Parents' search for help is marked by a period of uncertainty and questions prior to receiving confirmation of the diagnosis ${ }^{3}$. Parents notice the first symptoms at around 15 months ${ }^{4}$ and may wait for up to a year before seeking help $p^{2}$. From the moment they first start to worry about their child's development, three and a half years may go by between seeking professional help and obtaining confirmation of a diagnosis of $\mathrm{ASD}^{2}$. Nevertheless, parents may react positively to the diagnosis, since it establishes a sense of control and enables interventions to be initiated ${ }^{10}$. Cultural differences, however, may be associated with parents' failure to identify the symptoms in their child as symptoms of autism, regarding them as a "developmental delay or communication problem" or "no problem at all", leading to disagreements and tension between professionals and parents ${ }^{5,11}$ and to diagnostic errors by the professionals ${ }^{12}$.

Receiving a diagnosis of ASD in a child constitutes a relevant event in parents' lives, and communicating this information is an important and difficult task. Giving and receiving a diagnosis of ASD represent key points insofar as the possibility of the child's development is concerned and with respect to parents' adherence to the child's planned treatment. During the diagnostic process, the time spent in evaluation, the assistance offered when communicating diagnosis and the communication styles used by the professionals may increase parents' satisfaction, affecting their functioning, which will have an effect on the care they give their child ${ }^{13}$. The parents' functioning and their reaction to the situation of having a child with ASD need to be evaluated as part of the diagnosis communication, taking into consideration that this process will differ from region to region, in the different countries ${ }^{13}$.

Considering culturally informed care ${ }^{14}$ as representing a relevant factor in medical practice, knowing how parents receive and react to their child's diagnosis of ASD may contribute towards greater comprehension of the diagnostic process, to an improvement in diagnosis communication and optimization of the decisions regarding treatment. In this respect, the objective of the present study was to understand how parents react to the diagnosis of autism in their child, and the manner in which the diagnosis was revealed, as well as the method through which the researcher perceived this communication.

\section{METHODS}

\section{Design}

This qualitative study used a narrative approach that sought to understand how parents experience the moment at which they receive a diagnosis of autism. The parents' narratives were obtained at semi-structured interviews ${ }^{15}$. Ethnographic participant observations were also used ${ }^{15}$ to complement the information obtained at the interviews.

\section{Sample}

The base population consisted of the parents of children enrolled at a special needs school for young people with ASD and the parents of children undergoing evaluation at a university healthcare service specialized in the diagnosis of ASD in the city of Salvador, Bahia, Brazil. This was a convenience sample, the size of which was determined by data saturation. The participants were volunteers of both sexes and there were no limitations with respect to age.

\section{Settings}

The special needs school for young people with ASD, setting of this study, is a philanthropic, nonprofit organization. At the time of data collection, 175 students were enrolled in the school, 150 of whom were male. The students ranged in age from 2 years and 5 months to 32 years. Most, however, were children. In the university healthcare service specialized in diagnosing ASD the diagnostic evaluation is performed by a team, which evaluates the child and delivers the anamnesis to the parents and the completes the questionnaires, for about 90 to $120 \mathrm{~min}$. A case study is conducted on the same day of the evaluation, and the diagnosis is communicated to the parents at the next appointment, one to three weeks afterwards.

\section{Data collection}

Parents at the special needs school were invited by the principal investigator to interviews, which were held in a private room at the school. The script of the interview consisted of the six questions. For this study, the answers to the question: How did you feel when you were told of your child's diagnosis? were evaluated. Participant observation at the university healthcare service was made possible through prior referral from the unit's coordinators and occurred at the 
moment diagnosis was given to the child's mother or father by a resident doctor.

Between July 16 and November 16, 2015, 9 fathers and 21 mothers, including three couples, were interviewed, at the ASD specialized school. The interviews were recorded and meticulously entered into a computer program. The files are to remain archived for five years. The interviews lasted from 13 to 117 minutes, with a median duration of 35 minutes. In the university service specialized in ASD diagnosis, twelve cases were observed at the moment at which the diagnosis of ASD was communicated to the child's parent(s): in 7 cases to the mothers, in 1 case to a father and in 4 cases to couples, making a total of 11 mothers and 5 fathers. This stage of the study took place between August 27, 2015 and April 7, 2016 except for the months of December and February.

\section{Data analysis}

All the interviews were conducted and transcribed by the principal investigator; therefore, her relationship with the data began as early as that stage in the study. The procedure used to codify the narratives generated from the interviews sought to relate fragments from the narratives with key ideas, referred to as categories, as proposed by Gibbs ${ }^{16}$. Not only was the content of the narratives obtained from the questions posed by the interviewer taken into consideration, but also information related to the general idea of how the parents felt and how they reacted when they were given their child's diagnosis of ASD ${ }^{17}$. Following a systematic reading of all the interviews, categories were created and the contents of the narratives contained therein were grouped together. The fragments of the narratives were highlighted at each interview and correlated with the categories that emerged during the systematic reading. Each fragment of narrative was identified as $\mathrm{M}$ (mother) or $\mathrm{F}$ (father) followed by a number, e.g. M11, F5. In the data analysis, an attempt was made to identify patterns or trends within the categories, and to correlate the content of the narratives with the data obtained at participant observation and with the reference literature ${ }^{15,17}$.

\section{Ethical aspects}

The School of Medicine and Public Health's postgraduate program's internal review board approved the study protocol on July 13, 2015 under reference number 1.146.792, CAAE 44094515.9.0000.5544 in accordance with the ethical requirements of Resolution 466 of the National Health Council $^{18}$. Participants were provided with information regarding the study and signed an informed consent form prior to enrollment.

\section{RESULTS}

Overall, 21 mothers and 9 fathers were interviewed. The mothers' ages ranged from 21 to 82 years, while the fathers were between 30 and 50 years of age. All the fathers were married compared to only $57 \%$ of the mothers. In relation to schooling, $44 \%$ of the fathers had graduated from high school and 33\% had graduated from university, while 62\% of the mothers had completed at least high school. Only one of the fathers was unemployed compared to $67 \%$ of the mothers. Mean family income was three minimum salaries for the fathers and two and a half minimum salaries for the mothers.

Participant observation of the moment at which diagnosis was delivered included the cases of 12 children aged 11 months to 5 years and of one 18-year old girl, and involved 11 mothers and 5 fathers. Regarding the fathers' education, 40\% were university graduates, $40 \%$ were illiterate and 20\% had failed to complete primary education. Their mean family income was two minimum salaries. With respect to the mothers, 55\% had completed high school and 64\% had at least some high school education. Their mean family income was also two minimum salaries.

The data analysis produced four categories around the questions related to the objective of this study: "in search of a diagnosis", "impact of receiving the diagnosis", "patterns of diagnosis communication", and "coping strategies". The categories are listed below and supplemented with segments of the mothers' narratives being identified as $M$ (mother) followed by a number. In the case of the parents who were observed when receiving the diagnosis, a segment of speech from the one mother is cited and identified with the letters $\mathrm{MO}$ followed by a number. The names of the individuals interviewed were changed in the database to preserve the identity of the study participants.

\section{In search of a diagnosis}

The mothers expressed their belief that the prevalence of autism is increasing; however, doctors remain unprepared to deliver the diagnosis. Some mothers said that professionals mentioned a "problem" in their child but failed to name it. In some situations, the professionals suggested that the child's problem lay in the fact that the mothers did not know how to bring up the child; in other cases, they believed that the mothers were inventing problems that didn't exist. Most of the mothers were forced to trail from one doctor to another prior to receiving a diagnosis.

"I went to a pediatrician because I noticed that his behavior was different. She said that he was badly brought up, [...]. Another doctor said that I was finding faults in my child; that there was nothing wrong with him". (M1, a mother with a 10-year old autistic child).

"With Dr. Carlito, we talked; he informed me of the diagnosis; that brought a mixture of relief, sensations; my crying was different; I knew what he had [...]". (M3, mother of a 19year old autistic child). 


\section{Impact of receiving the diagnosis}

Almost all the mothers interviewed expressed feelings of sadness, anguish, despair and hopelessness when made aware of the diagnosis. These feelings were described as a shock; a devastating moment; the worst experience of their lives. With respect to the fathers, the majority described the moment as difficult and sad, a shock, a blow.

"When I was given the information confirming the diagnosis, I couldn't breathe. I just cried; I couldn't see the horizon. [... . . I just imagined that he would be unable to do anything; it was as if he had died". (M8, mother of a 4-year old autistic boy).

Observation of the parents when they were given the diagnosis detected expressions of suffering in the majority of the mothers, with tears, reports of anguish, sadness, concern and shock. Some mothers, however, showed no signs of any emotional impact and limited themselves to asking questions or showing interest in the reports referring the child for treatment and for the special needs school. None of the fathers showed any strong signs of emotion when being given the diagnosis.

\section{Patterns of diagnosis communication}

With respect to the interviews, the patterns of diagnosis communication are described from the mothers' point of view, while, insofar as participant observation is concerned, descriptions are based on the investigator's perspective. None of the fathers touched on this subject in the interviews; however, the mothers described communication as adequate or inadequate. By observing diagnosis communication, two patterns were clear: one that focused on biomedical aspects and the other that went beyond the biomedical aspects.

The mothers considered the pattern of communication as inadequate when the professional was pretentious, explained little, highlighted the negative aspects, and failed to offer any comfort or support, upsetting the women.

"When I heard the diagnosis, it was difficult, [...]. The way in which it was given was harsh; the tactlessness that the doctor sometimes has, [...]; the way of putting it; your son this, [...]. She was talking nonstop and that stuck with me [...]. It was very difficult". (M9, mother of a 22-year old autistic boy).

The mothers considered the pattern of diagnosis communication adequate when the professional was able to soften the negative effect of the diagnosis. Those professionals provided them with information about the problem, calmed them down, comforted them, were sensitive to the mother's pain and, principally, gave them hope with respect to the child's development with treatment.

"When the doctor said that they were autistic, the ground opened up beneath me and I fell into an abyss; I went into despair; I cried, but the doctor said that there was treatment, that some children make progress, have an almost independent life, that treatment would help. She calmed me down, but it was very difficult". (M5, mother of 6-year old triplets, one girl and two boys. Both boys are autistic).

From the investigator's perspective, when learning of the diagnosis the parents' reactions partially reflected the way in which the consultation was conducted. Lack of any emotional expression appeared not necessarily to mean the absence of an impact and may depend on the way in which diagnosis is communicated. Two patterns of diagnosis communication were observed: one focused on biomedical aspects and the other going beyond the biomedical aspects.

The pattern that focused on biomedical aspects was the most commonly seen pattern. This pattern may result in the parents distancing themselves emotionally during the consultation. Technical content is predominant. Diagnosis communication focuses on providing information and explaining symptoms, delivering reports, and referring for treatment and for social benefits. There is emphasis on the child's potential despite the presence of ASD, albeit with little comfort and support, suggesting that the professionals who deliver the diagnosis to parents need to be better prepared to deal with parents' pain, frustration and suffering, and to communicate difficult news. Consequently, parents are shielded by technical information that creates a barrier, keeping their emotion under control.

From the investigator's perspective, the pattern of diagnosis communication that goes beyond the biomedical aspects enables the professional to offer an environment of comfort, comprehension and emotional support, allowing the parents to express their fear and distress at receiving the diagnosis. This expression of suffering allows the professional to present possible ways of dealing with these fears by comforting the parents and, when required, providing technical guidance. In such cases, the explanations are part of comforting but do not substitute it nor serve as a means of concealing emotions.

\section{Coping strategies}

Most of the participants interviewed sought ways in which to minimize the impact of receiving the diagnosis: acquiring information, accepting the diagnosis, taking their child for treatment, seeking professional help for themselves and finding strength.

When receiving the diagnosis, attempts to minimize the impact with compensatory statements were seen as coping strategies, e.g. better a mild case than a severe one; better autism than mental retardation; despite the difficulties, with God's help we'll manage. Some mothers and/or fathers demonstrated signs of denial by justifying their child's symptoms as being a behavioral reaction to the environment.

"No mother wants to have a child with a deficiency. We want a normal child. If his condition was more severe, I don't know what would happen". (MO3, mother of a 4-year old autistic boy). 


\section{DISCUSSION}

In the narratives, within the category "In search of a diagnosis", the parents complained of the medical professionals' unpreparedness, which in their opinion often delayed diagnosis. Furthermore, the professionals tended to blame the parents for their child's condition: either the mothers did not know how to bring up their children or they were inventing a problem that didn't exist. These findings are in agreement with the results of other studies. In one study conducted in two municipalities in the state of São Paulo, Brazil, the mothers believed that the professionals ignored their opinion on the possible symptoms of autism, while classifying their autistic children as spoiled or unruly ${ }^{19}$. They also stressed how difficult it is to obtain a diagnosis and how parents are obliged to trail from one professional to another, with none being adequately prepared to detect the disorder rapidly ${ }^{19}$. A study carried out in a clinic specialized in ASD at the Federal University of São Paulo indicated that pediatricians disregarded the mothers' concerns about the development of their children, thus delaying the diagnosis ${ }^{20}$. In the United States, professionals providing care to children of Latin American origin failed to take parents' concerns into account, leading parents to lose trust in the medical system ${ }^{11}$. In different sociocultural settings, parents considered the diagnostic process very slow and reported consulting with many professionals prior to receiving their child's diagnosis of ASD ${ }^{21}$. In Sweden, most mothers considered the diagnostic process to be fast and effective ${ }^{22}$. On the other hand, there are contexts in which parents may delay seeking help. A study conducted with Latin American immigrants in the United States showed that the parents delayed seeking evaluation because of the stigma that surrounds mental illness ${ }^{23}$. In view of the diversity of studies in this field pointing out different results, it is possible to assume that many factors are involved, such as economic, cultural and also those linked to the health services quality available in each society.

In relation to the "impact of receiving the diagnosis", feelings of sadness, anguish, despair, hopelessness and shock were reported by almost all the participants interviewed in this study. In the literature, similar data have been repeatedly reported in different sociocultural settings. The moment at which a diagnosis of ASD is given is a significant event for parents, laden with anguish and sadness, and a trigger of anxiety in their lives ${ }^{21}$. Receiving the news can be devastating, causing fear, sadness and anxiety as parents react to the process of losing the future they had imagined for their child ${ }^{24}$, with negative feelings of an unpredictable future for those children ${ }^{3}$. In a study conducted in the United Kingdom², 84\% of the parents classified the diagnostic process as very stressful or quite stressful. A study carried out in Sweden showed that parents reported positive feelings at finally obtaining a diagnosis, with relief, sadness and the impression that even if they had known what was to come, it would have been difficult to prepare themselves for it ${ }^{22}$.

Participant observation at the moment of diagnosis showed that the parents were confused by the reports and by the substantial amount of new information they were required to process. Some mothers failed to show any emotional impact, limiting themselves to asking questions or showing interest in the reports provided, probably reflecting the predominantly technical attitude of the doctors who were giving the diagnosis. Even in settings in which the parents were satisfied with the diagnostic process, difficulties were reported in processing the information received, and parents considered that insufficient time was given for them to obtain answers to their questions $\mathrm{s}^{22}$.

According to the mothers interviewed, the "patterns of diagnosis communication" were inadequate in most cases and adequate in a few situations. In the pattern considered inadequate, the professional is unprepared to give the news. He/she points out negative aspects, is pretentious, does not offer support and provides little clarification. When the professional provides information on the problem, when he/she offers comfort and gives hope regarding the child's future, the mothers consider communication adequate. Other studies have shown that the stress of the diagnostic process can be moderated when the parents feel better supported ${ }^{2}$ and when diagnosis is given early, in a private setting and with empathy, emphasizing the child's positive characteristics and providing hope in relation to treatment ${ }^{21,25}$. Dissatisfaction with the diagnostic process, on the other hand, is associated with the presence of the child in the room and with the diagnosis being given in writing or by telephone?

In the investigator's perspective, it was clear that the diagnosis communication pattern that focuses on biomedical aspects, the most common pattern, led the parents to distance themselves emotionally during the consultation, while the pattern that went beyond the biomedical aspects, the pattern in which an atmosphere of comfort and emotional support was provided, enabled the parents to express their feelings and emotions related to the diagnosis. Most healthcare professionals feel unprepared to communicate a child's difficult diagnosis to parents, and parents generally feel unprepared to receive such a diagnosis. Therefore, the way in which this diagnosis is given has to be an acquired skill that improves over time and is individualized to each situation ${ }^{25}$. Parents appreciate receiving written information and welcome the opportunity to ask questions. They value being put at ease, being listened to and having sufficient time in which to absorb the information provided ${ }^{21}$. A study conducted with a Latin-American population in Oregon ${ }^{11}$ found that even after receiving the diagnosis, parents were unsure what ASD meant, what their child actually had and what they should do from that moment on. This 
finding appears to reflect the way in which diagnosis was communicated, with the information provided failing to meet parents' requirements.

In relation to "coping strategies", the parents considered it important to be informed, to accept the diagnosis, to take their child for treatment as quickly as possible and to seek professional help to give them strength.

When receiving the diagnosis, the following coping mechanisms were noted: rather a mild case than a severe one; rather autism than mental retardation; and despite the difficulties, with God's help I will cope. In addition, some parents refused to believe the diagnosis, justifying or downplaying their child's behavior. Another study ${ }^{22}$ also reported that after a diagnosis of ASD parents wanted to begin interventions as quickly as possible. Study ${ }^{23}$ reported that Latin-American immigrants in the United States tended not to accept the diagnosis of ASD at first. A study ${ }^{5}$ indicated that some non-Western immigrant parents failed to accept the diagnosis of autism suggested by the professionals, even when the degree of autism was severe. Attributing meaning to the behavior of a child with ASD may represent a strategy for coping with the diagnosis ${ }^{24}$.

\section{CONCLUSIONS}

The narratives of the mothers interviewed suggest that there are delays in the diagnosis of ASD due to the medical professionals' lack of knowledge and/or skills. Learning of their child's diagnosis exerts a negative emotional impact on the parents, which can be softened by coping strategies and by diagnosis communication that in addition to supplying technical information offers comfort, emotional support and hope regarding the child's development. Of the coping strategies, denial may represent a form of living with the child's difficulties, retaining hope and expectations in relation to his/her positive aspects. Perception of this need may help the technical team establish a doctorpatient relationship that satisfies parents' needs, feelings and meanings, their doubts and anguishes, rather than the informative biomedical approach, which is educational and prescriptive. In a search for coping strategies, parents made it clear that they need to receive care in order to care for their children and this is an important aspect to be remembered not only at the time of diagnosis but throughout the entire process of caring for individuals with ASD.

\section{INDIVIDUAL CONTRIBUTIONS}

Milena Pereira Pondé - Was the researcher advisor and contributed substantially in the conception and design of the study, critically reviewed the intellectual content of this manuscript and approved its final version for publishing.

Márcia Cristina Maciel de Aguiar - Contributed substantially in the conception and design of the study, analyzed and interpreted the data, wrote the manuscript, and approved its final version for publishing.

\section{DISCLOSURE STATEMENT}

The authors have no financial relationships to disclose.

\section{ACKNOWLEDGEMENTS}

The authors are grateful to all participants.

\section{REFERENCES}

1. American Psychiatric Association (APA). Diagnostic and statistical manual of mental disorders. 5th ed. Arlington, VA: American Psychiatric Publishing; 2013.

2. Crane L, Chester JW, Goddard L, Henry LA, Hill E. Experiences of autism diagnosis: a survey of over 1000 parents in the United Kingdom. Autism. 2016;20(2):153-62.

3. Onzi FZ, Gomes RF. Autism spectrum disorder: the importance of diagnosis and rehabilitation. Caderno Pedagógico. 2015;12:188-99.

4. Zanon RB, Backes B, Bosa CA. Parents' perception of the first symptoms of autism. Psic Teor Pesq. 2014;30(1):25-33.

5. Pondé MP, Rousseau C. Immigrant children with autism spectrum disorder: the relationship between the perspective of the professionals and the parents' point of view. J Can Acad Child Adolesc Psychiatry. 2013;22(2):131-8.

6. Novaes CM, Pondé MP, Freire AC. Control of psychomotor agitation and aggressive behavior in patients with autistic disorder: a retrospective chart review. Arq Neuropsiquiatr. 2008;66(3b):646-51.

7. Silva M, Mulick JA. Diagnosticando o transtorno autista: aspectos fundamentais e considerações práticas. Psicol Cienc Prof. 2009;29(1):116-31.

8. Pondé MP, Novaes CM, Losapio MF. Frequency of symptoms of attention deficit and hyperactivity disorder in autistic children. Arq Neuropsiquiatr. 2010;68(1):103-6.

9. Pondé MP, Matos ML, Oliveira CC. Prevalence of attention-deficit/hyperactivity disorder, oppositional defiant disorder and conduct disorder in children with autism spectrum disorder. Braz J Med Hum Health. 2017;5(2):39-46.

10. Semensato MR, Bosa CA. Relatos de pais de crianças com autismo sobre a rede de apoio formal: aspectos da elaboração parental do diagnóstico. Revista Educação Especial. 2013;26(47):651-64.

11. Zuckerman KE, Sinche B, Mejia A, Cobian M, Becker T, Nicolaidis C. Latino parents' perspectives of barriers to autism diagnosis. Acad Pediatr. 2014;14(3):301-8.

12. Mandell DS, Ittenbach RF, Levy SE, Pinto-Martin JA. Disparities in diagnoses received prior to a diagnosis of autism spectrum disorder. J Autism Dev Disord. 2007;37(9):1795-802.

13. Reed P, Osborne LA. Diagnostic practice and its impacts on parental health and child behaviour problems in autism spectrum disorders. Arch Dis Child. 2012;97(10):927-31.

14. Kleinman A, Benson P. Anthropology in the clinic: the problem of cultural competency and how to fix it. PLOS Med. 2006;3(10): e294.

15. Creswell J. Qualitative inquiry and research design: choosing among five approaches. Los Angeles: Sage; 2013.

16. Gibbs GR. Analyzing qualitative data. London: Sage; 2008.

17. Pondé MP, Mendonça MS, Caroso C. Methodological proposal for a dual level analysis of qualitative data. Hist Cienc Saude-Manguinhos. 2009;16(1):129-43. 
18. Brasil. Ministério da Saúde. Conselho Nacional de Saúde. Resolução nº 466/12. Brasilia; 2012.

19. Favero-Nunes MA, Santos MA. Itinerário terapêutico percorrido por mães de crianças com transtorno autístico. Psicol Reflex Crít. 2010;23(2):208-21.

20. Ribeiro SH, Paula CS, Bordini D, Mari JJ, Caetano SC. Barriers to early identification of autism in Brazil. Rev Bras Psiquiatr. 2017;39(4):352-4.

21. Abbott M, Bernard P, Forge J. Communicating a diagnosis of Autism Spectrum Disorder - a qualitative study of parents' experiences. Clin Child Psychol Psychiatry. 2013;18(3):370-82.
22. Carlsson E, Miniscalco C, Kadesjö B, Laakso K. Negotiating knowledge: parents' experience of the neuropsychiatric diagnostic process for children with autism. Int I Lang Commun Disord. 2016;51(3):328-38

23. Blanche El, Diaz J, Barretto T, Cermak SA. Caregiving experiences of Latino families with children with Autism Spectrum Disorder. Am J Occup Ther. 2015;69(5):1-11.

24. Semensato MR, Bosa CA. Parental beliefs about autism and it's evolution in the diagnostic communication process. Pensando Fam. 2014;18(2):93-107.

25. Sethi N, Ladores S. Disclosing a child's difficult diagnosis to parents: a review of literature. J Nurs Pract Appl Rev Res. 2017;7:49-57. 


\section{Autism: impact of the diagnosis in the parents}

Autismo: impacto do diagnóstico nos pais

DOI: 10.1590/0047-2085000000276

J Bras Psiquiatr. 2020;69(3):149-55

Where you read:

Received in: Apr/25/2020. Approved in: May/6/2020

Should read:

Received in: Nov/1/2018. Approved in: May/6/2020

DOI: 10.1590/0047-2085000000295 